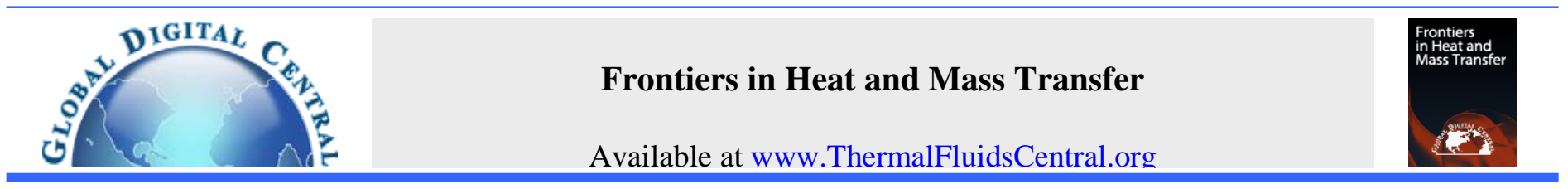

\title{
FLOW CHARACTERISTICS OF WET NATURAL GAS IN DIFFERENT THROTTLING DEVICES
}

\author{
Xuewen $\mathrm{Cao}^{\mathrm{a}, \mathrm{b},{ }^{*}}$, Qi Chu ${ }^{\mathrm{a}, \mathrm{b}}$, Xiaodan Song ${ }^{\mathrm{a}, \mathrm{b}}$, Yuxuan $\mathrm{Li}^{\mathrm{a}}{ }^{\mathrm{ab}}$, Jiang Bian ${ }^{\mathrm{a}, \mathrm{b}}$ \\ a Shandong Provincial Key Laboratory of Oil \& Gas Storage and Transportation Safety, Qingdao 266580, China \\ ${ }^{b}$ College of Pipeline and Civil Engineering, China University of Petroleum (East China), Qingdao 266580, China
}

\begin{abstract}
Wet natural gas widely exists in the natural gas industry, and the selection of throttling devices plays an important role in wet natural gas transportation. In order to study the flow field characteristics of different throttling devices in wet natural gas pipelines, a set of Laval nozzles, orifice plates, and plate valves have been designed. The standard $k-\varepsilon$ model was selected for numerical simulation. By changing inlet pressure, inlet temperature or volume fraction of water-liquid, the pressure field and temperature fields of different throttling devices were obtained, and the influence of the presence of a shockwave on the flow fields of the throttling devices was analyzed. Different throttling devices have significantly different operating characteristics. Therefore, appropriate throttling devices should be selected in different conditions in order to control the pressure of wet natural gas transportation and reduce gas hydrate formation. The present simulation results show that under identical conditions, the throat pressure and temperature of the Laval nozzle are the lowest, the throat pressure of the orifice plate is the highest, and the throat temperature of the plate valve is the highest.
\end{abstract}

Keywords: wet natural gas; throttling device; shockwave; numerical simulation

\section{INTRODUCTION}

Rapid growth in natural gas demand has increased the exploitation of natural gas fields, and more and more natural gas pipelines have been built (Karimi et al. 2009). The throttling of wet gas exists widely in the industrial fields of power production, nuclear energy, and refrigeration (Yuan et al. 2016). In the natural gas industry, due to the high wellhead pressure, throttling is usually adopted to reduce pressure to a safe range. Besides, in order to prevent corrosion and blockage in the pipeline caused by liquid precipitation during the transportation, dehydration and de-hydrocarbon treatments are required before natural gas enters the pipeline. The throttling separation method has characteristics of large operation flexibility, simple process flow and equipment, and convenient maintenance, which is a main technology in natural gas dehydration and dehydrogenation treatment methods. However, the throttling of wet natural gas needs further understanding in the field of oil and gas.

Significant research has focused on the throttling of wet natural gas using different throttling devices. Bian et al. (2018a) investigated study the condensation process of methane and carbon dioxide mixture gas in nozzle. Jassim et al. (2008a, 2008b) studied the flow characteristics of high-pressure gas by changing the shape of the nozzle. Liu et al. (2015, 2017) studied the variations of pressure and temperature in a Laval nozzle in high-speed compressible flow. Xiao et al. (2017) pointed out that the temperature decreased when the wet natural gas flows through the Laval nozzle. Some researchers (Bian et al. 2018b; Cao et al. 2019a) proposed that under the same ratio of inlet pressure to outlet pressure, the temperature of the gas in a Laval nozzle drops significantly more than that of other throttling devices. Hou et al.
(2018) showed that orifice thickness has little influence on the throttling effect and that the orifice diameter should be designed to be as small as possible. Liu et al. (2012) established a calculation method for the pressure drop caused by throttling during the killing well. Ding et al. (2012) analyzed the influence of the structural parameters of a venturi tube on the pressure drop using numerical simulation. Wang et al. (2018) studied the effects of the structural parameters of multistage recirculating nozzles on throttling characteristics.

Significant research has been done on shockwaves in throttling devices. Sławomir et al. (2014) proposed that the formation of shockwaves in the expanding section of the Laval nozzle is caused by excessive back pressure. Katanoda et al. (2007) proposed that the optical visualization by the schlieren method clarifies that when the throat upstream stagnation pressure divided by the back pressure is between 2 and 4, shock waves exist in the nozzle. Liu et al. (2016) proposed that when other parameters are consistent, the shockwave position moves towards the outlet of the Laval nozzle with the decrease of outlet pressure. Zhang et al. (2014) presented that the shockwave position can be controlled by adjusting the outlet pressure. Bian et al. (2016) proposed that the shockwave moves forward as the pressure ratio between the inlet and outlet of the Laval nozzle decreases. Setoguchi et al. (2010) determined that within a certain pressure ratio range, the location of shockwave in the nozzle has hysteresis behavior during the formation process. Zhang et al. (2019a, 2019b) investigated the shockwave phenomenon caused by the condensation of steam.

Although considerable research has been devoted to throttling devices, much less attention has been paid to flow characteristics of wet gas in different throttling devices. The aim of this research is to study the pressure and temperature fields of the wet gas under different operating conditions and in different throttling devices. The present 
study has important theoretical value and practical significance for the improvement of natural gas transportation and purification processes and the prevention of gas hydrate formation.

\section{DESIGN OF THE THROTTLING DEVICES}

In the process of wet natural gas passing through a throttling device in a pipeline, a local shrinkage state is formed in the throttling device which increases the flow velocity of the fluid. At the same time, continuous fluid through the throttling devices will produce a sudden change in pressure, which will lead to changes in temperature. This phenomenon is known as the Joule-Thomson effect. In this paper, a Laval nozzle, orifice plate, and plate valve are selected for comparative analysis. The Laval nozzle consists of a stable section, a convergent section, a throat, and an expanding section. The convergent section is designed using the Witozinsky equation (Yang et al. 2014), as shown in Eq. (1).

$$
r=\frac{r_{c r}}{\sqrt{1-\left[1-\left(\frac{r_{c r}}{r_{1}}\right)^{2}\right] \frac{\left(1-\frac{x^{2}}{L^{2}}\right)^{2}}{\left(1+\frac{x^{2}}{3 L^{2}}\right)^{3}}}}
$$

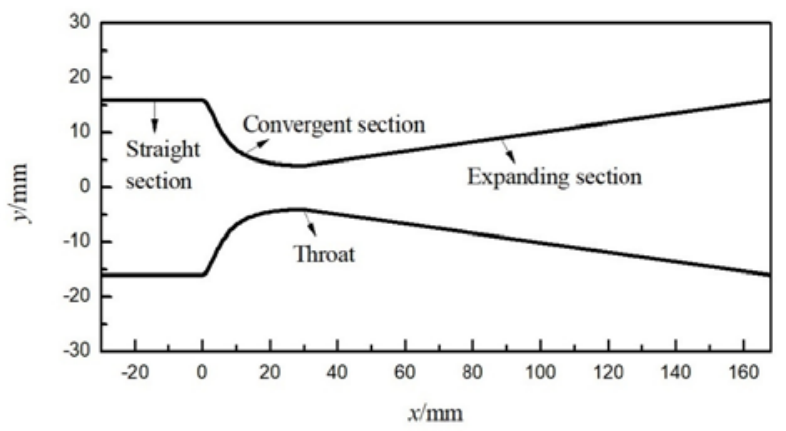

(a)

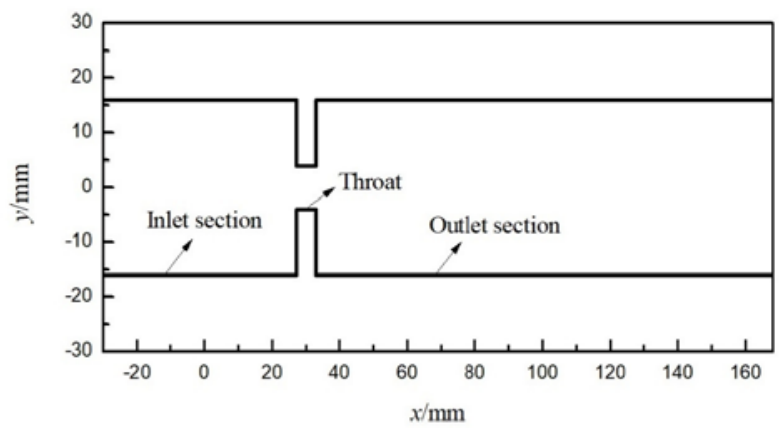

(b)

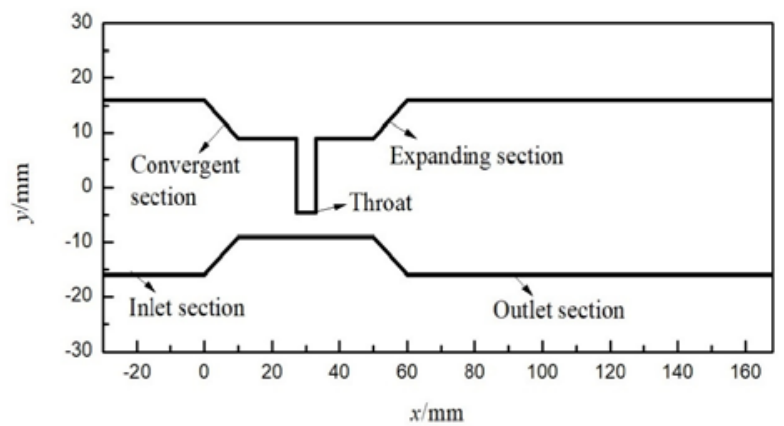

(c)

Fig. 1 The geometries of the three throttling devices. (a) Laval nozzle; (b) orifice plate; (c) plate valve.
The divergent section is designed as a taper to restore the diameter of circulation. The length of the stable section, the convergent section, and the divergent section are $30 \mathrm{~mm}, 30 \mathrm{~mm}$ and $138 \mathrm{~mm}$, respectively. The radius of the stable section and the outlet radius of the Laval nozzle are $16 \mathrm{~mm}$, and the radius of the throat is $4 \mathrm{~mm}$. The inlet radius, the outlet radius, and the throat area of the orifice plate and Laval nozzle are equal. The thickness of the orifice plate is $6 \mathrm{~mm}$. Because the throat shape of the plate valve is not circular, the throat area of the designed plate valve is equal to that of the Laval nozzle and the orifice plate. The plate valve opening is $25 \%$, and the plate is $4.5 \mathrm{~mm}$ away from the pipe wall. The convergent section and the divergent section are designed as cones. The geometries of three throttling devices are shown in Fig. 1.

\section{MATHEMATICAL MODEL}

In the present study, the FLUENT software was selected for the numerical simulations. The density-based compressible flow formulation of the Euler equations have proven to be very successful for the analysis of high-speed flows (Campobasso et al. 2018; Cao et al. 2019b). Because the medium in the throttling device is compressible high-speed fluid, the density-based solver in FLUENT was adopted in this paper. In the simulations presented here, the primary phase is natural gas, and the secondary phase is water-liquid. A second-order upwind scheme was used to increase the accuracy of calculation (Bian et al. 2018c, 2019). The absolute criteria of simulation residuals were set to be $10^{-5}$ for all the dependent variables.

\subsection{Governing Equations}

The governing equations describing the flow in throttling devices involve the continuity, momentum, and energy equations. These equations are given in Eqs. (2)-(4):

$$
\begin{aligned}
& \frac{\partial \rho}{\partial t}+\frac{\partial}{\partial x_{j}}\left(\rho u_{j}\right)=0 \\
& \frac{\partial}{\partial t}\left(\rho u_{i}\right)+\frac{\partial}{\partial x_{j}}\left(\rho u_{j} u_{i}\right)=\frac{\partial}{\partial x_{j}}\left[\mu\left(\frac{\partial u_{j}}{\partial x_{i}}+\frac{\partial u_{i}}{\partial x}-\frac{2}{3} \delta_{i j} \frac{\partial u_{j}}{\partial x_{j}}\right)\right]-\frac{\partial p}{\partial x_{i}}+\frac{\partial}{\partial x_{j}}\left(-\rho \overline{u_{i}^{\prime} u_{j}^{\prime}}\right) \\
& \frac{\partial}{\partial t}(\rho E)+\frac{\partial}{\partial x_{j}}\left(\rho u_{j} E+u_{j} p\right)=\frac{\partial}{\partial x_{j}}\left(k_{e f f} \frac{\partial T}{\partial x_{j}}+u_{i} \tau_{\text {eff }}\right)
\end{aligned}
$$

\subsection{Turbulence Model}

In order to satisfy the required accuracy without large computational cost, the standard $k-\varepsilon$ model is used to solve for turbulence in the calculation of the flow field (Han et al. 2019a, 2019b; Wen et al. 2012). This model has the advantages of wide application, good economy, and reasonable accuracy. The $k$ and $\varepsilon$ equations describing the dispersed turbulence mode are as follows:

$$
\begin{aligned}
& \frac{\partial}{\partial t}(\rho k)+\frac{\partial}{\partial x_{i}}\left(\rho k u_{i}\right)=\frac{\partial}{\partial x_{j}}\left[\left(\mu+\frac{\mu_{t}}{\sigma_{k}}\right) \frac{\partial k}{\partial x_{j}}\right]+G_{k}-\rho \varepsilon \\
& \frac{\partial}{\partial t}(\rho \varepsilon)+\frac{\partial}{\partial x_{i}}\left(\rho \varepsilon u_{i}\right)=\frac{\partial}{\partial x_{j}}\left[\left(\mu+\frac{\mu_{t}}{\sigma_{\varepsilon}}\right) \frac{\partial \varepsilon}{\partial x_{j}}\right]+\frac{\varepsilon}{k}\left(C_{1 \varepsilon} G_{k}-C_{2 \varepsilon} \rho \varepsilon\right)
\end{aligned}
$$

\subsection{Boundary Conditions}

The turbulence intensity and hydraulic diameter are selected to specify the turbulence boundary conditions. The formula for turbulence intensity can be derived from empirical correlations and is as follows:

$$
I=\frac{\mu^{\prime}}{\mu_{\text {avg }}}=0.16\left(\operatorname{Re}_{D H}\right)^{-\frac{1}{8}}
$$


The inlet and outlet boundary types are set as pressure-inlet and pressure-outlet, respectively. Besides, the operating pressure is set to be $0.1 \mathrm{MPa}$.

Pressure inlet: under three different parameter settings: the inlet pressure are set to be from $0.15 \mathrm{MPa}$ to $0.35 \mathrm{MPa}$, the inlet temperature is set to be from $283 \mathrm{~K}$ to $303 \mathrm{~K}$. The volume fraction of water-liquid is set to be from 0.01 to 0.09 . The turbulence intensity and hydraulic diameter are $5 \%$ and $0.032 \mathrm{~m}$, respectively. The outlet pressure is held constant at $0.10 \mathrm{MPa}$, and the temperature is set to be $293 \mathrm{~K}$.

\subsection{Grid Independence Verification}

Unstructured meshes are used for the three throttling devices, and a local mesh refinement method is employed in the boundary layer regions, as shown in Fig. 2. The grid independence is verified using the simulated pressure distributions. With the Laval nozzle as an example, the number of cells in each of the test grids was 149 787, 206 172, 275 805 and 373830 . The pressure distribution of the centerline is presented in Fig. 3. There was little difference between the simulation results with 275805 cells and with 373830 cells. While the result accuracy is higher with higher grid resolution, the computational efficiency is lower. Therefore, the grid system with 275805 is used for the numerical simulations. Likewise, the number of cells used for the orifice plate and the plate valve are 177512 and 304 109, respectively.

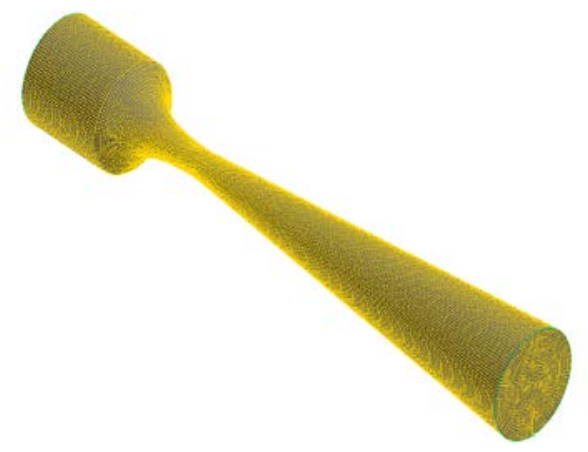

(a)

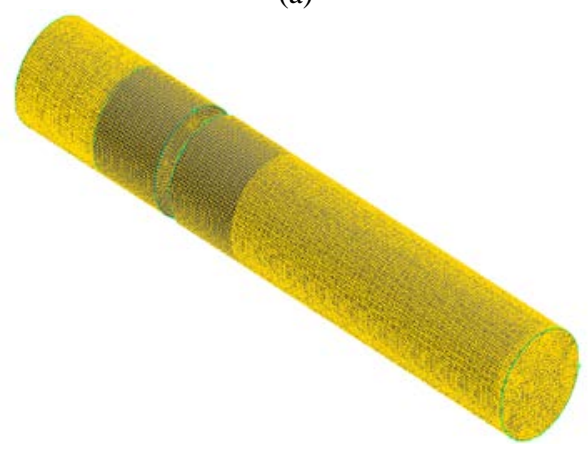

(b)

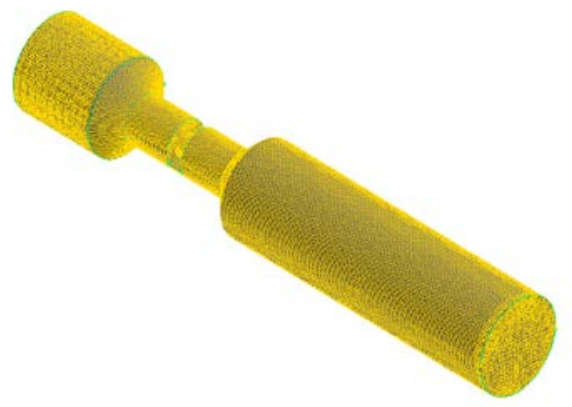

(c)

Fig. 2 The mesh generation of the three throttling devices. (a) Laval nozzle; (b) orifice plate; (c) plate valve.

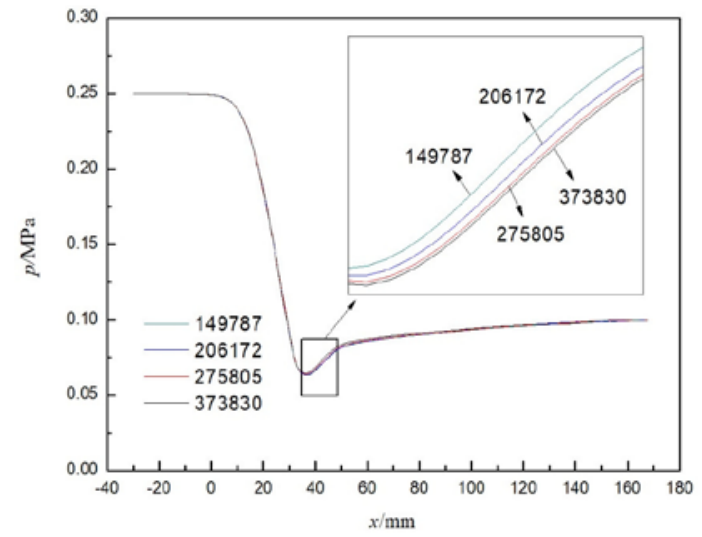

Fig. 3 Pressure distributions in the nozzle with different grid numbers.

\section{RESULTS AND DISCUSSION}

\subsection{Effects of Throttling Devices on the Throttling Characteristics}

The temperature and pressure fields and shockwave position for each of the three throttling devices were analyzed for an inlet temperature of $293 \mathrm{~K}$, a liquid volume fraction of 0.05 , an inlet pressure of $0.25 \mathrm{MPa}$, and backpressure of $0.10 \mathrm{MPa}$. Fig. 4 (a) shows the distribution of axial static pressure in the three throttling devices.

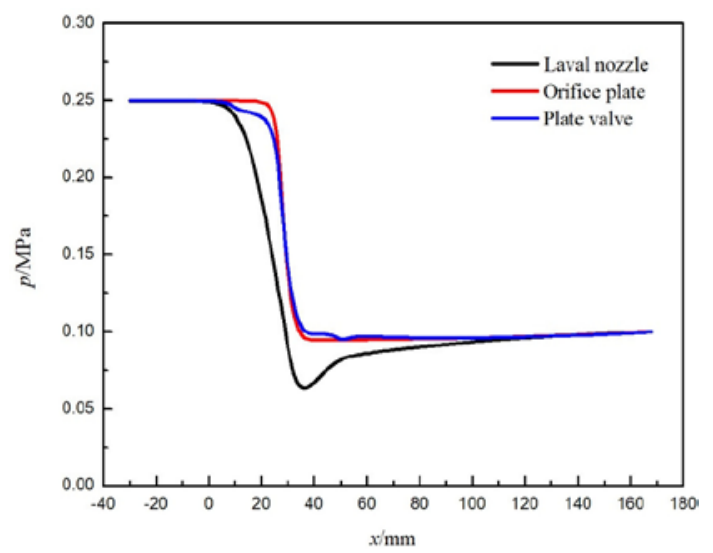

(a)

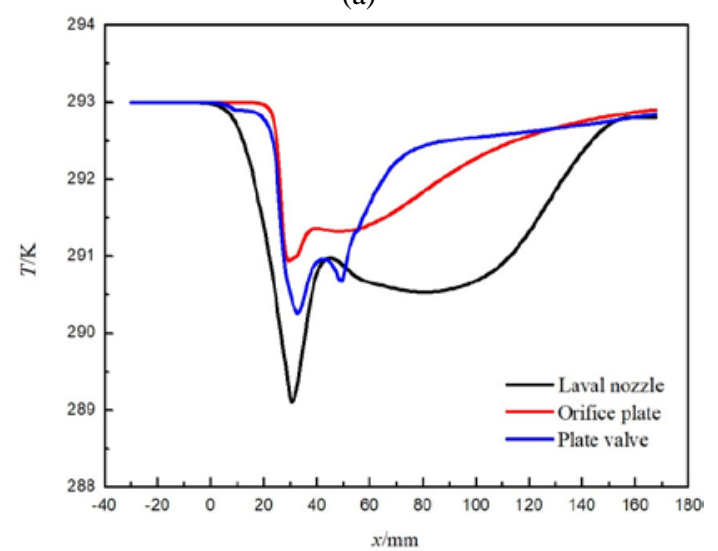

(b)

Fig. 4 Flow characteristics of wet natural gas in three throttling devices. (a) pressure distributions; (b) temperature distributions.

Because the flow area remains unchanged in the inlet section, the pressure drop is not significant. The pressure decreases when wet natural gas enters the convergent section of the Laval nozzle and plate valve and recovers gradually after entering the expanding section. 
Because the orifice geometry has no convergent section, the curve slope of pressure drop is the largest. The Witozinsky curve of the Laval nozzle is smooth, so the pressure drop is relatively gentle. As can be seen from Fig. 4 (a), the minimum pressures of Laval nozzle, orifice plate, and plate valve are 0.064 MPa, 0.094 MP, and 0.095 MPa, respectively. Compared with the orifice plate and plate valve, the minimum pressure of the Laval nozzle is the lowest. It can be seen that the convergent section of different throttling devices has an obvious influence on the pressure distribution.

Fig. 4 (b) shows the distribution of axial temperature in the three throttling devices. There is no obvious temperature change in the inlet section of the devices. The temperature then decreases or increases with the change of flow area. The temperature increases briefly due to the impact of the shockwave. As can be seen from Fig. 4 (b), the minimum temperatures of the Laval nozzle, orifice plate, and plate valve are 289 K, $291 \mathrm{~K}$, and $290 \mathrm{~K}$, respectively. Compared with the Laval nozzle and plate valve, although the temperature of the orifice plate decreases fastest in the throat, the overall temperature drop of the orifice plate is the lowest. Furthermore, the orifice plate has the highest minimum temperature at the shockwave position, and the temperature rises slowly after the shockwave. The temperature drop of the Laval nozzle is larger and smoother than the plate valve in the convergent section. As well, the temperature of the Laval nozzle at the shockwave position is lower than the plate valve. Although the temperatures of the Laval nozzle and plate valve rise, the plate valve rises faster.

\subsection{Effects of Inlet Pressure on the Throttling Characteristics}

In order to examine the effect of inlet pressure, the inlet pressures were set to 0.15 MPa, 0.20 MPa, 0.25 MPa, 0.30 MPa, and 0.35 MPa, for an inlet temperature of $293 \mathrm{~K}$, a liquid volume fraction of 0.05 , and backpressure of $0.10 \mathrm{MPa}$. The pressure field, temperature field and shockwave position were analyzed. Fig. 5 shows the distribution of axial static pressure in the three throttling devices for each of the investigated inlet pressures. When the other conditions are the same, as the inlet pressure increases, the pressure at the throat position of the three throttling devices decreases. Subsequently, the pressure gradually rises to $0.1 \mathrm{MPa}$. As can be seen from Fig. 5, the pressure drop of the Laval nozzle is the most obvious with the increase of inlet pressure. For the Laval nozzle, as the inlet pressure increases from $0.15 \mathrm{MPa}$ to 0.35 $\mathrm{MPa}$, the shockwave pressure decreases from $0.087 \mathrm{MPa}$ to $0.039 \mathrm{MPa}$, and the shockwave position moves forward from $x=33 \mathrm{~mm}$ to $x=40$ $\mathrm{mm}$. This indicates that the larger the inlet pressure is, the more significant influence it has on the pressure drop. As the inlet pressures increase from $0.15 \mathrm{MPa}$ to $0.35 \mathrm{MPa}$, the minimum pressures of the orifice plate and the plate valve decrease from $0.098 \mathrm{MPa}$ to $0.090 \mathrm{MPa}$ and $0.098 \mathrm{MPa}$ to $0.092 \mathrm{MPa}$, respectively. Unlike the Laval nozzle, the orifice plate and the plate valve have no obvious shockwave.

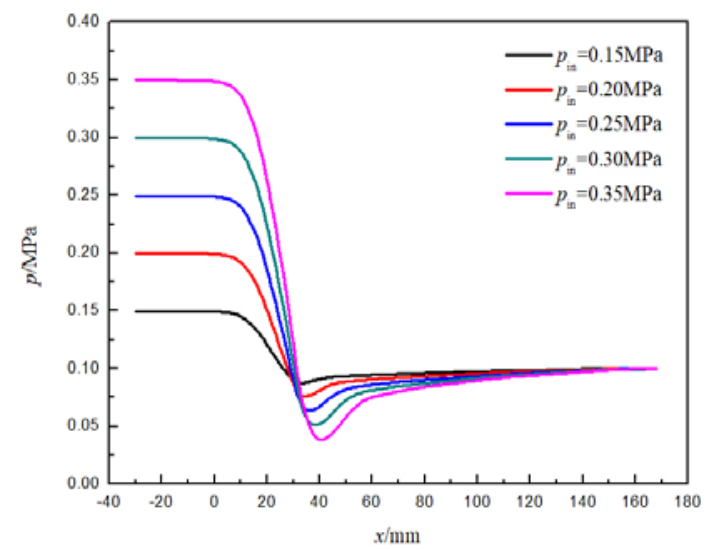

(a)

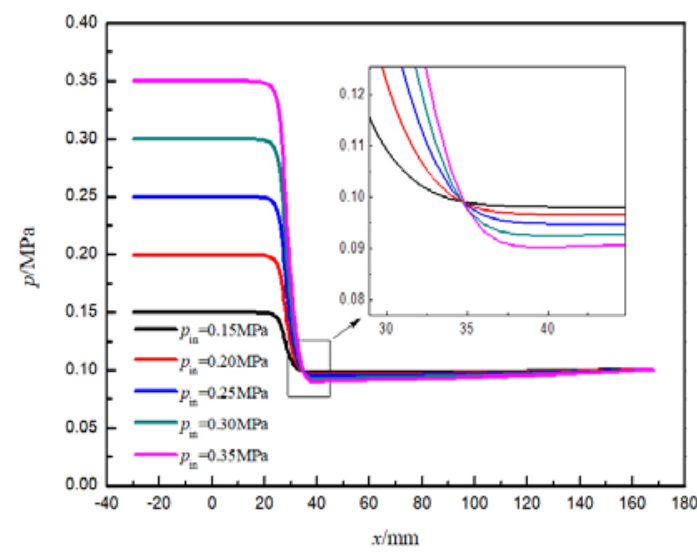

(b)

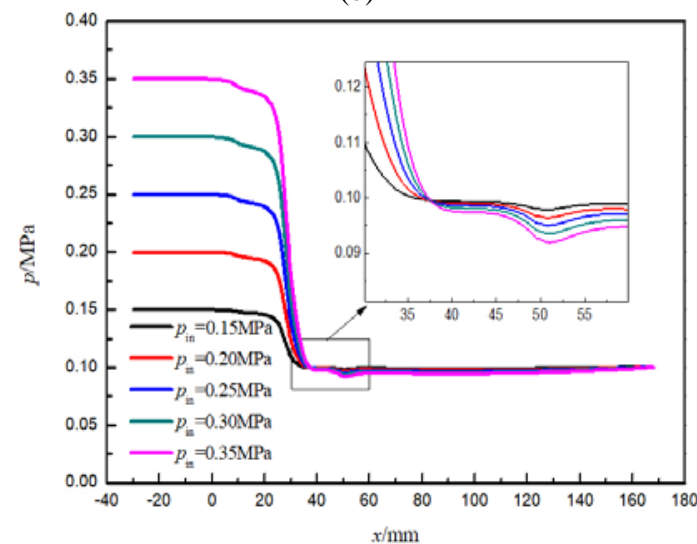

(c)

Fig. 5 Pressure distributions of wet natural gas under different inlet pressures in three throttling devices. (a) Laval nozzle; (b) orifice plate; (c) plate valve.

Fig. 6 shows the distribution of axial temperature in each of the three throttling devices when the inlet pressure is varied. Because of the Joule-Thomson effect, throttling not only results in a decrease in pressure but also leads to a decrease in temperature. When other conditions are held constant, as the inlet pressure increases, the temperature of the three throttling devices decreases except for the inlet section, and the temperature drop was most pronounced at the throat. As well, the shockwave has a greater influence on the temperature field of the three throttling devices. Compared to the orifice plate and plate valve, the shockwave of the Laval nozzle has the most obvious effect on the temperature field. When the inlet pressure is increased from 0.15 MPa to $0.35 \mathrm{MPa}$, the temperature of the wet natural gas in the Laval nozzle rises higher due to the shockwave. Additionally, the position of the temperature minimum moves forward from $x=28 \mathrm{~mm}$ to $x=34$ $\mathrm{mm}$. At the same time, the larger the inlet pressure, the more obvious influence it has on the temperature field. The temperature decreases slowly after the shock position and then rises again due to the heat transfer with the wall. When the inlet pressure is increased from 0.15 $\mathrm{MPa}$ to $0.35 \mathrm{MPa}$, the position of the temperature minima in the orifice plate and plate valve both move forward from $x=30 \mathrm{~mm}$ to $x=34 \mathrm{~mm}$. Although the orifice plate and the Laval nozzle have similar temperature fields, the shockwave has little effect on the temperature field in the orifice plate. As can be seen from Fig. 6 (c), because of the design of the plate valve, the temperature fluctuation is large. With the increase of the inlet pressure, the temperature fluctuation at the shockwave position increases. 


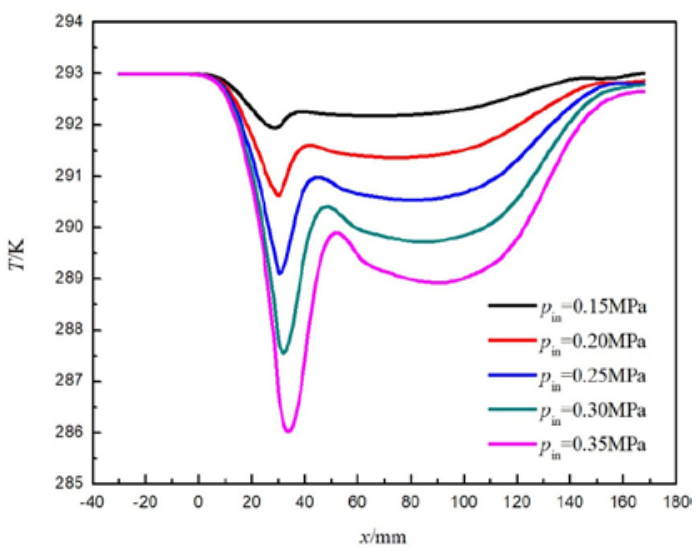

(a)

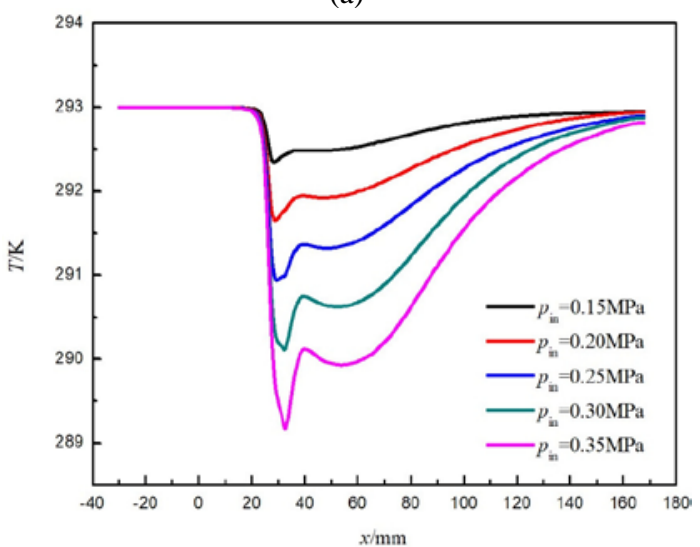

(b)

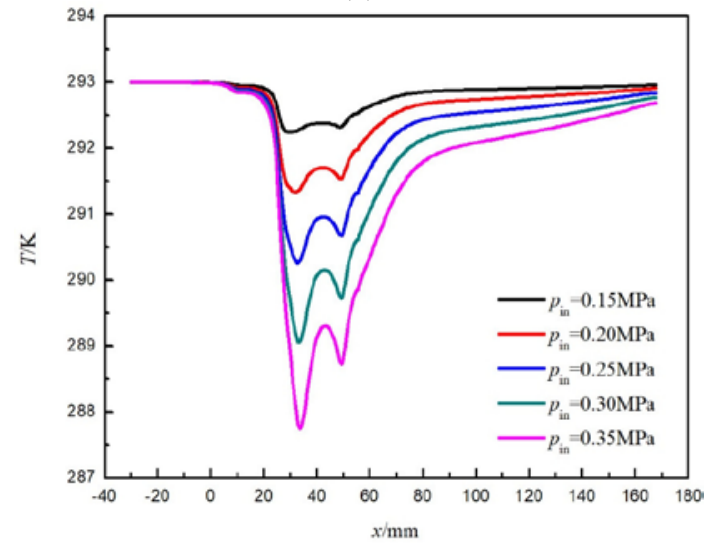

(c)

Fig. 6 Temperature distributions of wet natural gas under different inlet pressures in three throttling devices. (a) Laval nozzle; (b) orifice plate; (c) plate valve.

\subsection{Effects of inlet temperature on the throttling characteristics}

In order to study the effect of inlet temperature on the throttling characteristics, the simulations were performed for inlet temperatures of 283 K, 288 K, 293 K, 298 K, and 303 K. The other properties were held constant. The inlet pressure was set to $0.25 \mathrm{MPa}$; the backpressure was set to $0.10 \mathrm{MPa}$, and the liquid volume fraction was set to 0.05 . The pressure field, temperature field and shockwave position in the three throttling devices were analyzed. Fig. 7 shows the distribution of axial static pressure in three throttling devices when the inlet temperatures are set to $283 \mathrm{~K}, 288 \mathrm{~K}, 293 \mathrm{~K}, 298 \mathrm{~K}$, and $303 \mathrm{~K}$, respectively. As can be seen from Fig. 7, the pressure of the inlet section in the Laval nozzle is unchanged at $0.25 \mathrm{MPa}$. As the inlet temperature is decreased from $303 \mathrm{~K}$ to $283 \mathrm{~K}$, the shockwave pressure decreases from $0.065 \mathrm{MPa}$ to $0.063 \mathrm{MPa}$, respectively. The inlet temperature is positive correlated with the pressure at the throat position in the Laval nozzle. However, the overall pressure variation with the change of the inlet temperature is small. In the divergent section, the pressure gradually rises to $0.1 \mathrm{MPa}$. Compared to the Laval nozzle, the pressure drops of the orifice plate and plate valve are basically unchanged with the change of the inlet temperature. This observation indicates that the change of inlet temperature has little effect on the pressure drop of the orifice plate and plate valve.

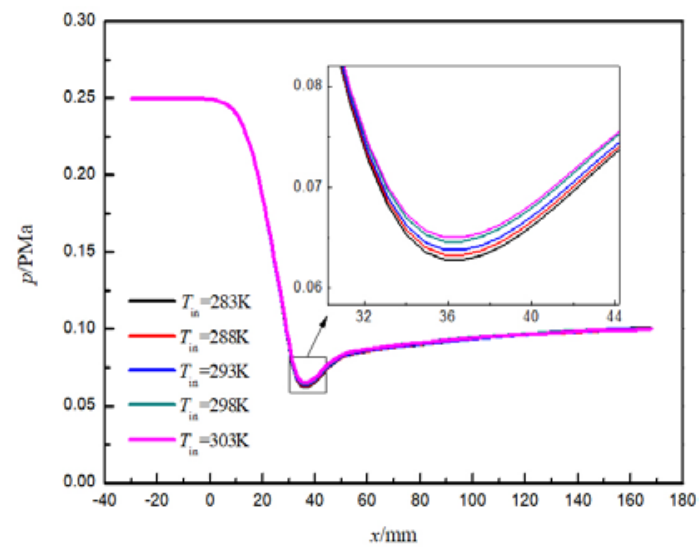

(a)

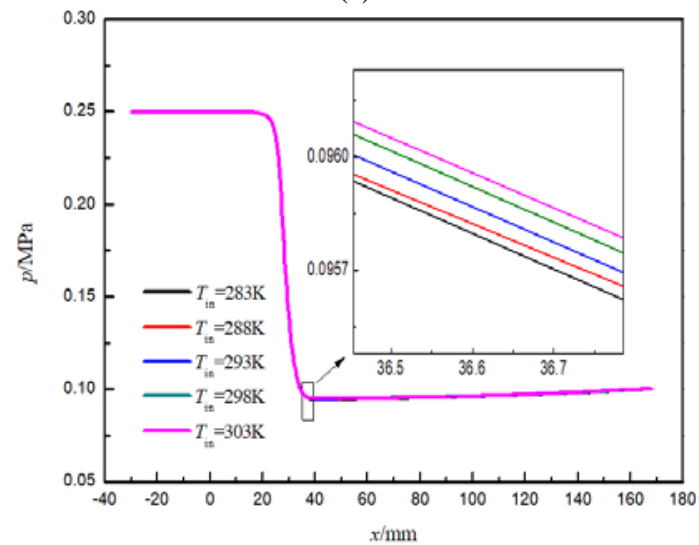

(b)

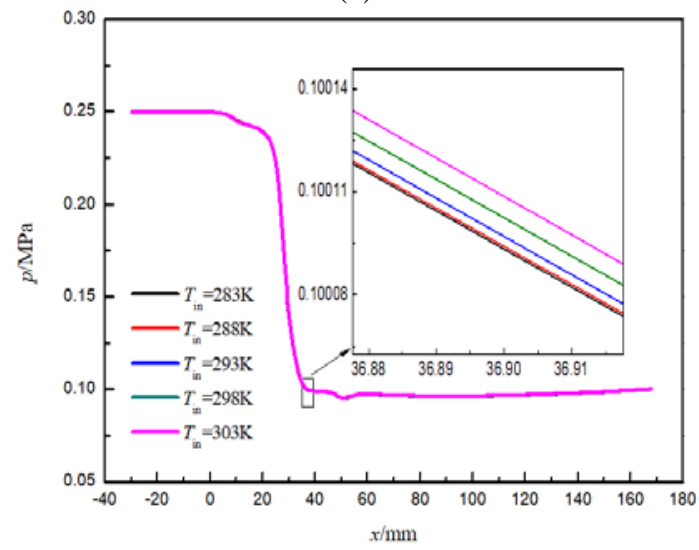

(c)

Fig. 7 Pressure distributions of wet natural gas under different inlet temperatures in three throttling devices. (a) Laval nozzle; (b) orifice plate; (c) plate valve.

Fig. 8 shows the axial temperature distribution for the three throttling devices when the inlet temperature is set to $283 \mathrm{~K}, 288 \mathrm{~K}, 293$ $\mathrm{K}, 298 \mathrm{~K}$, and $303 \mathrm{~K}$. When the inlet temperature is decreased from 303 $\mathrm{K}$ to $283 \mathrm{~K}$, the throat temperature of the nozzle, orifice plate, and plate valve decreased from $299 \mathrm{~K}, 301 \mathrm{~K}$, and $300 \mathrm{~K}$ to $279 \mathrm{~K}, 281 \mathrm{~K}$, and $280 \mathrm{~K}$, respectively. The inlet temperature is a positive correlation 
between the temperature at the throat of the throttling devices. This temperature variation with the change of the inlet temperature is significant. In the divergent section of the throttling device, the temperature gradually moves towards the outlet temperature. Compared to the Laval nozzle, the temperatures at the outlet section of the orifice plate and plate valve are more affected by outlet temperature. Due to the design of the throttle devices, the temperature of the plate valve converges faster in the outlet section.

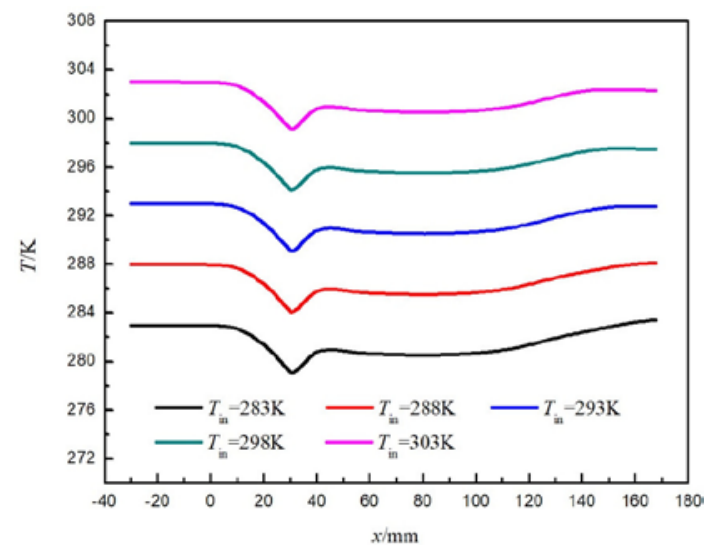

(a)

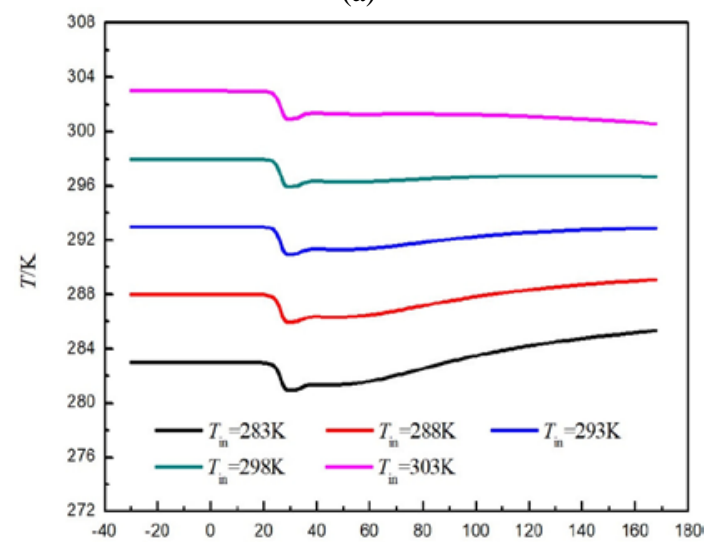

(b)

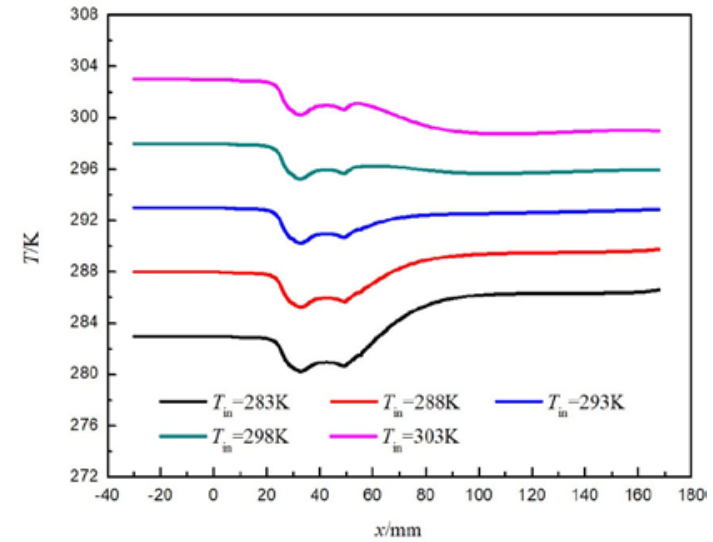

(c)

Fig. 8 Temperature distributions of wet natural gas under different inlet temperatures in three throttling devices. (a) Laval nozzle; (b) orifice plate; (c) plate valve.

\subsection{Effects of volume fraction of water-liquid on the throttling characteristics}

The liquid volume fraction was varied here to examine its effect on throttling characteristics. The volume fractions of water-liquid (defined as $\varphi$ ) are set to $0.01,0.03,0.05,0.07$ and 0.09 . The other parameters were held constant. The inlet temperature was $293 \mathrm{~K}$, the inlet pressure was $0.25 \mathrm{MPa}$, and the backpressure was $0.10 \mathrm{MPa}$. The pressure field, the temperature field, and the shockwave position in three throttling devices were analyzed.

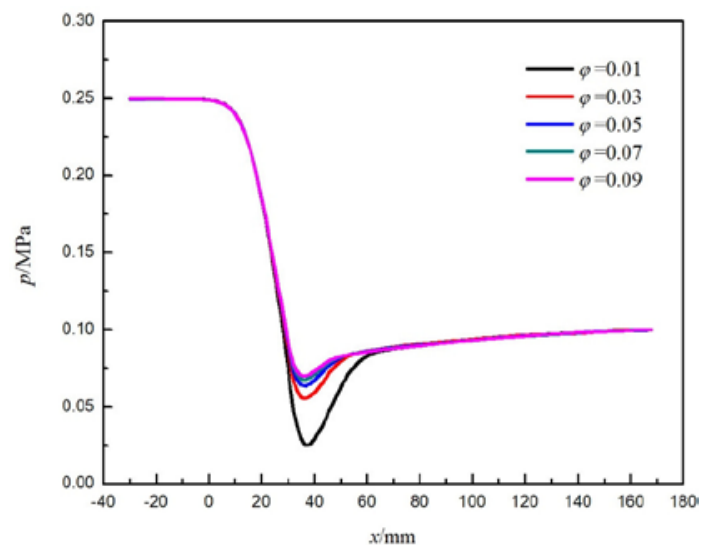

(a)

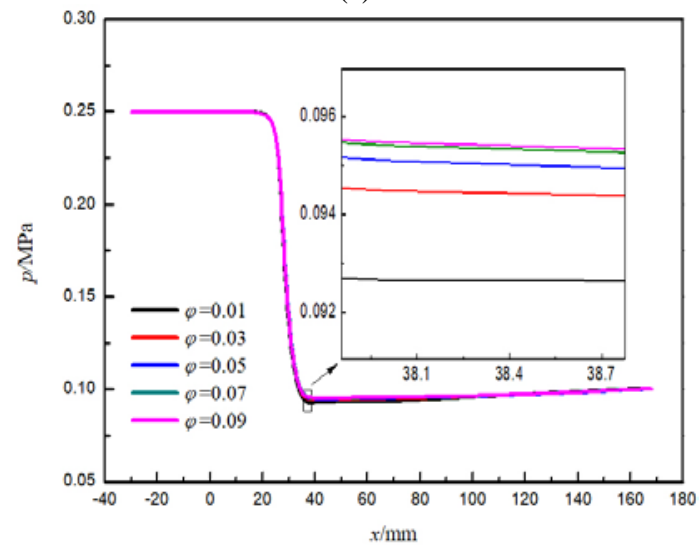

(b)

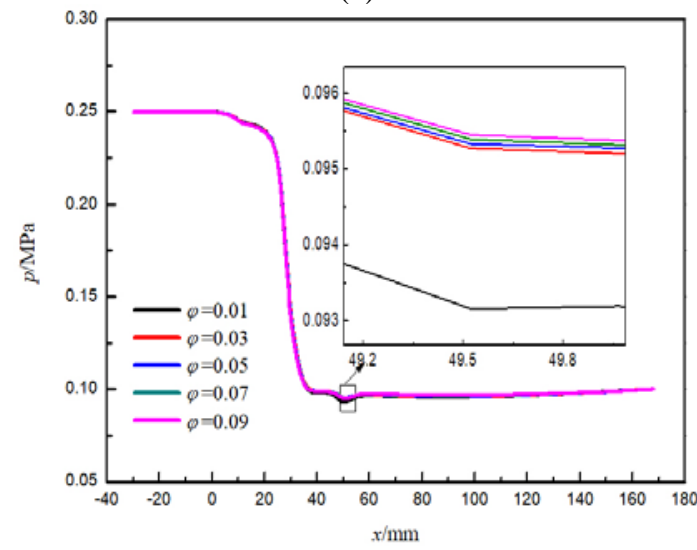

(c)

Fig. 9 Pressure distributions of wet natural gas under different volume fraction of water in three throttling devices: (a) Laval nozzle; (b) orifice plate; (c) plate valve.

Fig. 9 presents the distributions of axial static pressure in three throttling devices for volume fractions of 0.01, 0.03, 0.05, 0.07 and 0.09. From Fig. 9, the pressure of the inlet section in the three throttling devices is unchanged at $0.25 \mathrm{MPa}$. When the other conditions are held constant, the volume fraction of water-liquid is a positive correlation between the pressure at the throat position of the three throttling devices. In the divergent section, the pressure of three throttling devices gradually rises to $0.1 \mathrm{MPa}$. Compared with the orifice plate and plate valve, the pressure drop of the Laval nozzle is the most significant related to the decrease of the volume fractions of water-liquid. For the Laval nozzle, the smaller the volume fraction of water-liquid, the 
greater the pressure drop in the throat. When the liquid volume fraction is decreased from 0.09 to 0.01 , the shockwave pressure decreases from $0.070 \mathrm{MPa}$ to $0.025 \mathrm{MPa}$, and the shockwave position moves forward from $x=36 \mathrm{~mm}$ to $x=38 \mathrm{~mm}$. This indicates that the smaller the liquid volume fraction is, the more significant the influence of liquid volume fraction on pressure drop is. As the volume fraction is decreased from 0.09 to 0.01 , the minimum pressure for the orifice plate and plate valve decrease from 0.095 MPa to 0.093 MPa. Compared to the Laval nozzle, the orifice plate and the plate valve have no obvious shockwave.

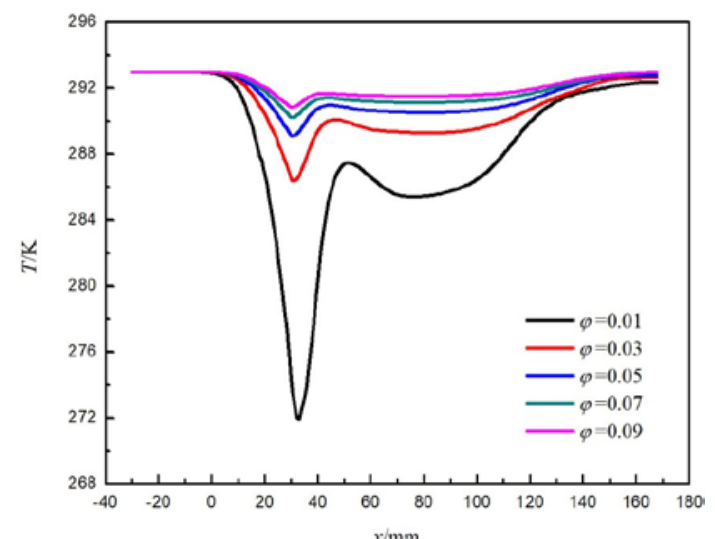

(a)

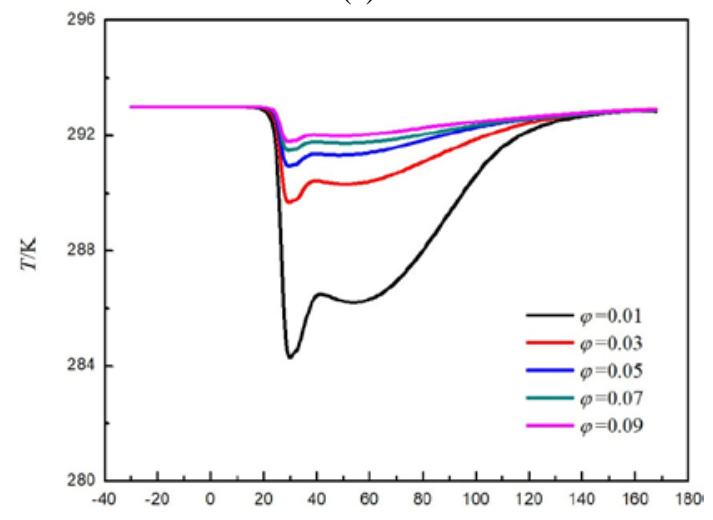

(b)

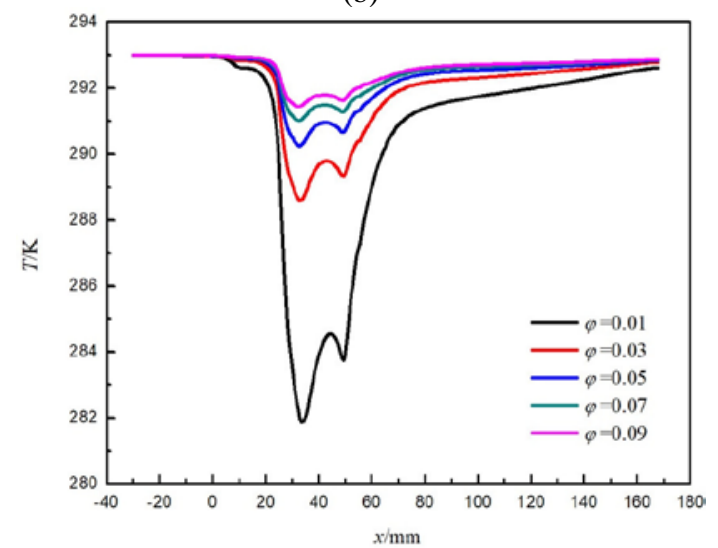

(c)

Fig. 10 Temperature distributions of wet natural gas under different $\varphi$ in three throttling devices. (a) Laval nozzle; (b) orifice plate; (c) plate valve.

Fig. 10 shows the axial temperature distributions of the three throttling devices for liquid volume fractions of $0.01,0.03,0.05,0.07$ and 0.09. Because of the Joule-Thomson effect, throttling not only results in a decrease in pressure but also leads to a decrease in temperature. When the other conditions are held constant, as the liquid volume fraction decreases, the temperature throughout the three throttling devices decreases with the exception of the inlet section, and the shockwave has a greater influence on the temperature field. Compared to the orifice plate and plate valve, the shockwave of the Laval nozzle has the most significant effect on the temperature field. When the liquid volume fraction is decreased from 0.09 to 0.01 , the temperature of wet natural gas in the Laval nozzle drops more due to shockwave and the position of minimum temperature moves forward from $x=30 \mathrm{~mm}$ to $x=33 \mathrm{~mm}$. In addition, the lower the liquid volume fraction is, the more obvious influence of liquid volume fraction on the temperature field is. The temperature decreases slowly after the shock and subsequently rises again due to the heat transfer with the wall. Although the orifice plate and the Laval nozzle have similar temperature fields, the shockwave has little effect on the temperature field in the orifice plate. As can be seen from Fig. 10 (c), because of the geometry of the plate valve, the temperature fluctuation in the plate valve is large. With a decrease in the liquid volume fraction, the temperature fluctuation at the shockwave position increases.

\section{CONCLUSIONS}

In the present study, the designs of three different throttling devices were carried out. The flow characteristics of wet natural gas in the throttling devices were obtained using numerical simulations. The influence of inlet flow parameters on the flow field were analyzed. Special attention was given to the shockwave position in the throttling devices. The main conclusions are summarized as follows.

For the case of an inlet temperature of $293 \mathrm{~K}$, a liquid volume fraction of 0.05 , an inlet pressure of $0.25 \mathrm{MPa}$, and a backpressure of $0.10 \mathrm{MPa}$, the throat pressure and temperature of the Laval nozzle were the lowest, the throat pressure of the orifice plate was the highest, and the throat temperature of plate valve is the highest.

For the present geometries, when other conditions are held constant, as the inlet pressure increases, the shockwave pressure and shockwave temperature decrease and the shockwave position moves towards the nozzle exit.

The pressure and temperature at the throat position are positive correlated with the inlet temperature. However, the change of inlet temperature has little effect on the throat pressure drop of the orifice plate and plate valve.

As the volume fraction of water-liquid decreases, the shockwave pressure and shockwave temperature decrease and the shockwave position moves downstream in throttling devices.

\section{ACKNOWLEDGEMENTS}

This study was supported by the National Natural Science Foundation of China (Grant No. 51874340) and the National Key R\&D Program of China (Grants No. 2016YFC0802302 and No. 2016YFC0802304).

\section{NOMENCLATURE}

$\begin{array}{ll}C_{l \varepsilon}, C_{2 \varepsilon} & \text { constants of } \varepsilon \text { equation }(-) \\ E & \text { total energy }(\mathrm{J}) \\ G_{k} & \text { turbulent kinetic energy }(\mathrm{J}) \\ I & \text { turbulence intensity }(-) \\ k_{e f f} & \text { effective thermal conductivity }\left(\mathrm{W} \cdot \mathrm{m}^{-1} \cdot \mathrm{K}^{-1}\right) \\ L & \text { length of the convergent section }(\mathrm{mm}) \\ p & \text { pressure }(\mathrm{Pa}) \\ r & \text { radius at an arbitrary cross-section of } x(\mathrm{~mm}) \\ r_{1} & \text { inlet radius }(\mathrm{mm}) \\ r_{C r} & \text { throat radius }(\mathrm{mm}) \\ R_{D H} & \text { Reynolds number }(-) \\ T & \text { temperature }(\mathrm{K}) \\ u & \text { velocity }\left(\mathrm{m} \cdot \mathrm{s}^{-1}\right) \\ x & \text { arbitrary length along the axis of the nozzle }(\mathrm{mm})\end{array}$


Greek Symbols

$\varphi \quad$ the volume fractions of water-liquid (-)

$\delta \quad$ Kronecker delta (-)

$\varepsilon \quad \quad$ turbulence dissipation rate (-)

$\mu \quad$ viscosity $\left(\mathrm{kg} \cdot \mathrm{m}^{-1} \cdot \mathrm{s}^{-1}\right)$

$\mu_{\text {avg }} \quad$ mean flow velocity $\left(\mathrm{m} \cdot \mathrm{s}^{-1}\right)$

$\rho \quad$ density $\left(\mathrm{kg} \cdot \mathrm{m}^{-3}\right)$

$\sigma_{k} \quad$ the turbulent Prandtl number of $\mathrm{k}(-)$

$\tau_{\text {eff }} \quad$ effective stress tensor (-)

\section{REFERENCES}

Bian J., Jiang W., Teng L., Liu Y., Wang S., Deng Z., 2016, "Structure Improvements and Numerical Simulation of Supersonic Separators," Chemical Engineering and Processing, 110, 214-219.

https://doi.org/10.1016/j.cep.2016.10.012

Bian J., Jiang W., Hou D., Liu Y., Yang J., 2018a, "Condensation Characteristics of $\mathrm{CH}_{4}-\mathrm{CO}_{2}$ Mixture Gas in a Supersonic Nozzle," Powder Technology, 329, 1-11.

https://doi.org/10.1016/j.powtec.2018.01.042

Bian J., Cao X., Yang W., Edem M. A., Yin P., Jiang W., 2018b, "Supersonic Liquefaction Properties of Natural Gas in the Laval Nozzle,” Energy, 159, 706-715.

https://doi.org/10.1016/j.energy.2018.06.196

Bian J., Cao X., Yang W.. Du H., Yin P., 2018c, “Effects of External Particles on the Liquefaction Property of Natural Gas in a Laval Nozzle," Powder Technology, 339, 894-902.

https://doi.org/10.1016/j.powtec.2018.08.077

Bian J., Cao X., Yang W., Song X., Xiang C., Gao S., 2019, "Condensation Characteristics of Natural Gas in the Supersonic liquefaction process,” Energy, 168, 99-110.

https://doi.org/10.1016/j.energy.2018.11.102

Campobasso M.S., Yan M., Bonfiglioli A., Gigante F.A., Ferrari L., Balduzzi F., Bianchini A., 2018, "Low-speed Preconditioning for Strongly Coupled Integration of Reynolds-averaged Navier-Stokes Equations and Two-equation Turbulence Models,” Aerospace Science and Technology, 77, 286-298.

https://doi.org/10.1016/j.ast.2018.03.015

Cao X., Bian J., 2019a, “Supersonic Separation Technology for Natural Gas Processing: A Review,” Chemical Engineering and Processing, 136, 138-151.

https://doi.org/10.1016/j.cep.2019.01.007

Cao X., Song X., Chu Q., Mu L., Li Y., Bian J., 2019b, “An Efficient Method for Removing Hydrogen Sulfide from Natural Gas Using Supersonic Laval Nozzle," Process Safety and Environmental Protection, 129, 210-221.

https://doi.org/10.1016/j.psep.2019.07.008

Ding J., Zhang X., Kou L., 2012, "Research and Optimization on the Venturi Tube Dynamic Throttling Element of New Flowmeter," Applied Mechanics and Materials, 231, 1218-1221.

https://doi.org/10.4028/www.scientific.net/AMM.229-231.1218

Han X., Zeng W., Han Z., 2019a, "Investigation of the Comprehensive Performance of Turbine Stator Cascades with Heating Endwall Fences,” Energy, 174, 1188-1199.

https://doi.org/10.1016/j.energy.2019.03.038

Han X., Zeng W., Han Z., Li P., Qian J., 2019b, "Effect of the Nonaxisymmetric Endwall on Wet Steam Condensation Flow in a Stator Cascade,” Energy Science and Engineering, 7, 557-572.

https://doi.org/10.1002/ese3.298
Hou C., Qian J., Chen F., Jiang K., Jin Z., 2018, "Parametric Analysis on Throttling Components of Multi-stage High Pressure Reducing Valve,” Applied Thermal Engineering, 128, 1238-1248. https://doi.org/10.1016/j.applthermaleng.2017.09.081

Jassim E., Abdi M. A., Muzychka Y., 2008a, “Computational Fluid Dynamics Study for Flow of Natural Gas Through High-pressure Supersonic Nozzles: Part 1: Real Gas Effects and Shockwave," Petroleum Science and Technology, 26, 1757-1772. https://doi.org/10.1080/10916460701287847

Jassim E., Abdi M. A., Muzychka Y., 2008b, “Computational Fluid Dynamics Study for Flow of Natural Gas Through High-pressure Supersonic Nozzles: Part 2: Nozzle Geometry and Vorticity,” Petroleum Science and Technology, 26, 1773-1785. https://doi.org/10.1080/10916460701304410

Katanoda H., Matsuoka T., Matsuo K., 2007, “Experimental Study on Shock Wave Structures in Constant-area Passage of Cold Spray Nozzle,” Journal of Thermal Science, 16, 40-45. https://doi.org/10.1007/s11630-007-0040-3

Karimi A., Abdi M. A., 2009, "Selective Dehydration of High-pressure Natural Gas Using Supersonic Nozzles,” Chemical Engineering and Processing, 48, 560-568.

https://doi.org/10.1016/j.cep.2008.09.002

Liu H., Yang X., Li C., Cheng X., 2012, “the Calculation Method and Experimental Research on Throttling Pressure Drop During Kill a Well," Applied Mechanics and Materials, 230, 495-498.

https://doi.org/10.4028/www.scientific.net/AMM.229-231.495

Liu X., Liu Z., Li Y., 2015, "Numerical Study of the High Speed Compressible Flow with Non-equilibrium Condensation in a Supersonic Separator,” Journal of Clean Energy Technologies, 3, 360366.

https://doi.org/10.7763/JOCET.2015.V3.224

Liu Y., Bian J., Guo X., Cao X., Jiang W., 2016, “Calculation of Shock-wave Position and Analysis of Refrigeration Performance in Laval Nozzle,” Cryogenics \& Superconductivity, 44, 14-18. https://doi.org/10.16711/j.1001-7100.2016.06.004

Liu X., Liu Z., 2017, "Numerical Investigation and Improvement Strategy of Flow Characteristics Inside Supersonic Separator," Separation Science and Technology, 53, 940-952. https://doi.org/10.1080/01496395.2017.1388256

Setoguchi T., Matsuo S., Alam A., Nagao J., Kim H. D., 2010, "Hysteretic Phenomenon of Shock Wave in a Supersonic Nozzle," Journal of Thermal Science, 19, 526-532.

https://doi.org/10.1007/s11630-010-0419-4

Sławomir D., Mirosław M., Krystian S., Michał, S., 2014, "Experimental Research on Wet Steam Flow with Shock Wave," Experimental Heat Transfer, 3, 417-429.

https://doi.org/10.1080/08916152.2014.913090

Wen C., Cao X., Yang Y., Li W., 2012, "Numerical Simulation of Natural Gas Flows in Diffusers for Supersonic Separators,” Energy, 37, 195-200.

https://doi.org/10.1016/j.energy.2011.11.047

Wang H., Li G., Zhao L., Wang Y., Liu Y., Liu Q., Wang M., Gao F., Cai M., 2018, "Throttle Characteristics of Multi-stage Circumfluence Nozzle During the Separate-layer Injection of $\mathrm{CO}_{2}$,” Petroleum, 4, 187197.

https://doi.org/10.1016/j.petlm.2017.08.003

Xiao R., Jin W., Han S., Li R., Cao X., 2017, “Numerical Simulation on Condensing Flow of Water Vapor of Wet Natural Gas Inside the Nozzle," Frontiers in Heat and Mass Transfer, 9, 6-14.

http://dx.doi.org/10.5098/hmt.9.6 
Yang Y., Wen C., Wang S., Feng Y., 2014, “Theoretical and Numerical Analysis on Pressure Recovery of Supersonic Separators for Natural Gas Dehydration,” Applied Energy, 132, 248-253.

https://doi.org/10.1016/j.apenergy.2014.07.018

Yuan C., Xu Y., Zhang T., Wei J., Wang H., 2016, “Experimental Research on Pressure Drop of Wet Gas Flow in Venturi,” Experimental Thermal and Fluid Science, 75, 183-188.

https://doi.org/10.1016/j.expthermflusci.2016.01.013

Zhang G., Zhang X., Wang F., Wang D., Jin Z., 2019a, “The Relationship Between the Nucleation Process and Boundary Conditions on Non-Equilibrium Condensing Flow Based on the Modified Model," International Journal of Multiphase Flow, 114, 180-191.

https://doi.org/10.1016/j.ijmultiphaseflow.2019.03.005
Zhang G., Wang F., Wang D., Wu T., Qin X., Jin Z., 2019b, "Numerical Study of the Dehumidification Structure Optimization Based on the Modified Model,” Energy Conversion and Management, 181, 159-177.

https://doi.org/10.1016/j.enconman.2018.12.001

Zhang Y., Wang S., Jing Z., Lv M., Luo X., 2014, "Design and Simulation of Supersonic Swirling Separator," Advanced Materials Research, 108, 1148-1153.

https://doi.org/10.4028/www.scientific.net/AMR.1008-1009.1148 